\title{
Trends and levels of childlessness among educated women in South Africa
}

\author{
Lesego Masebe and Mmatlala Ramosebudi
}

\author{
Population and Social Statistics, Statistics South Africa, Pretoria, South Africa \\ OlgaM@statssa.gov.za
}

\section{ABSTRACT}

In South Africa, fertility declined from 7 children per woman in the 1960's to 2.6 children per woman in 201I. The daunting situation is that in $201 \mathrm{I}$ whites and Indian/Asian fertility rates were below replacement level. Therefore, using South African censuses $200 \mathrm{I}$ and $20 \mathrm{II}$, the paper seeks to establish trends and levels of childlessness among educated women. The proportions of childlessness were calculated from women who reported that they never had children. Childlessness increased by $10 \%$ point between women aged 25-34. Black African women had the highest proportions of childlessness. The prevalence of childlessness was high among women with post higher degree and employed. The highest proportions of childlessness were evident among women who were never married. Within occupation variable, professionals and managers were childless. The majority of childless women were residing in Gauteng and Western Cape. Across all the socio-economic variables, the levels of childlessness increased substantially from $200 \mathrm{I}$ to $201 \mathrm{l}$.

Keywords: Fertility; Childlessness; Educated women; Socio-economic characteristics; South Africa

\section{Introduction}

In countries that have completed the demographic transition from high birth and death rates to low birth and death rates, childlessness by choice is growing and a 'child-free strategy' is gaining momentum (Biryukova, 20I5).

Contemporary childlessness is mostly voluntary and it can be a potential factor to low levels of fertility in recent decades, thus it warrants attention (Rowland and Merlo, 2000). Prevalence of childlessness is also an important indication of changing norms and value systems in a given society (Abbasi-Shavazi et al., 2009).

Life time childlessness remains a highly prevalent global condition. Infertility is estimated to affect between $8 \%$ and $12 \%$ of reproductive aged couples worldwide (Ombelet et al., 2008) with 9\% currently cited as the probable global average (Boivin et al., 2007). However, in some regions of the world, the rates of infertility are much higher, reaching $30 \%$ in some populations (Ombelet et al., 2008). This is true in a number of regions of high infertility prevalence such as South Asia, sub-Saharan Africa, the Middle East and North Africa, Central and Eastern Europe and Central Asia (Mascarenhas et al., 2012).

Amongst Organisation for Economic Cooperation and Development (OECD) countries the proportion of women aged 40-44 that are childless varies considerably. In countries such as Austria, Spain and the United Kingdom, $20 \%$ or more of women aged 40-44 are childless (OECD, 2015). Recent estimates of childlessness for the cohorts of women born around 1965 reveal that it has become an increasingly large group in Italy with a proportion of $25 \%$ and $20 \%$ for Germany and Finland respectively (OECD, 20II).

The problem of infertility (as indicated by childlessness) in sub-Saharan Africa has finally gained the attention. However, despite the importance of the issue, not many studies on voluntary childlessness have been carried out in Africa. In Sub-Saharan Africa, the prevalence of infertility, ranged from less than 10 percent in Togo and Rwanda to about 25 percent in Cameroon and Central African Republic of women aged 20-44 years (Larsen, 2000).

In South Africa childlessness continues to increase over time amongst all women of childbearing age (15-49 years). The high prevalence of childlessness is more pronounced among younger women aged I524 (Stats SA, 2015). Amongst most developed countries one in ten women have no children, and in South Africa the percentage of childless women in their late 40s approaches 5\% (World fertility report, 2009). While many of the childless young adults will have children later, it is expected that lifetime childlessness is also increasing all over, particularly in Europe (Frejka and Sardon, 2006).

Fertility in South Africa declined from 7 children per woman in the 1960's to 2.6 children per woman in $201 \mathrm{I}$ with fertility of whites and Indian population groups declining to a level of below replacement (Moultrie and Timaeus, 2002; Stats SA, 2015). Fertility rates below replacement level are threat to a country as the impact of an aging population and reduced economic growth resonates throughout the 
economy. Secondly, with rapidly aging populations, the ability to provide costly support services to the non-working elderly becomes more uncertain (Gustafsson and Kalwij, 2006).

The mean age at childbearing in South Africa increased from 20.8 in 1996 to over 28 across all population groups in 200 I (Sibanda and Zuberi, 1999, Moultrie and Dorrington, 2004). The postponement of childbearing to later ages has important implications in terms of health outcomes, increased infecundity and smaller completed family sizes (Schmidt et al., 20I2).

Therefore, in light of the down trends of fertility indicators the paper seeks to establish the trends and levels of childlessness amongst educated women in South Africa. Whereas previous literature has concentrated on the level of women's education and its impact on fertility, this paper adds a new dimension by also focusing on other socio economic factors such as field of education, occupation and employment.

\section{Literature review}

A considerable amount of research has been devoted to examining the voluntarily childless over the past 30 years. The research was based on among others, the characteristics of women, the prevalence, motivations, risk factors and stigmatization (Shapiro, 2014).

Nonetheless, voluntarily childlessness is a relatively understudied population and there are many research gaps in this field. Life time childlessness on the other hand is a life crisis with a wide range of socio-cultural, emotional, physical and financial problems (Greil et al., 20I0). It is defined as the incapacity to become pregnant among women aged I5-49 after 12 months of sexual intercourse without any contraception (Nygren et al., 20l I). It is difficult to calculate the rates of childlessness because involuntary and voluntary childlessness would have to be distinguished. However, childlessness has become increasingly common and among ages $18-50$ is estimated to range between $15 \%$ and $25 \%$ in many developed countries (Blackstone and Stewart, 20I2).

Demographic characteristics such as age is important in the study of fertility as the child bearing life span of a woman depend on it. As more couples delay childbearing, the issue of declining reproductive capacity with age becomes increasingly important (Merz and Liefbroer, 20I2). Recent United Kingdom (UK) data confirm that very few individuals report that they wish to remain childless, including people who are still childless in their thirties (Bhrolcháin et al., 2010; Berrington and Pattaro, 2014). Some of these men and women will not be able to have the children they desire due to age-related infecundability.

Higher female education has been found to relate to high prevalence of childlessness within and between countries. Merz and Liefbroer, (20I2) used data from the European Social Survey 2006 to examine the attitude towards voluntary childlessness in 20 countries. The study revealed that as more young adult women spend extended periods in education or pursuing career opportunities. Nicoletti and Tanturri, (2008) found that higher female education increased postponement of the first birth especially after the age 30 in ten European countries. On the other hand, findings from the Nordic countries reveal that more free gender relations and gender equity in the public sphere appear to increase fertility. For example, Persson, (2010) found signs of a remarkable fertility recovery due to women with high levels of education becoming mothers later in life.

The study by Adebowale and Palamuleni, (2014) which was conducted in Nigeria to determine the patterns of births interval, parity progression and completed fertility in Nigeria revealed that the mean children ever born diminishes as the level of education increases. It reduces from $6.7 \%$ among women with no formal education to $4.3 \%$ among women with higher education. (Udjo, 20l4) in his study of estimating demographic parameters from the 2011 South Africa population found out that although fertility is steadily declining amongst black African women, there are still disparities in the fertility levels between the four population groups. Black African women had the highest fertility rate. The levels suggest that Black African women had the lowest level of childlessness. Using June fertility supplement of the Census Bureau's Current Population Survey 2006 and 2008 in United State of America, Livingston and Cohn, (2010) found that $20 \%$ of white women aged $40-44$ were childless in 2008, the highest rate among racial and ethnic groups.

Place of residence have also been associated with childlessness. The study conducted among the states of India using District Level Household and Facility Survey data indicated that rural women have a higher percentage $(69.9 \%)$ of childlessness when compared with urban $(30.1 \%)$ women (Aiswarya and Moli, 2012). Contrary, the spatial analysis of data based on census $201 \mathrm{I}$ collected in South Africa indicated that fertility is higher among rural provinces than among urban provinces (Stats S.A, 2015).

Cavenaghi and Alves, (20/3) who analysed the tendencies of childlessness in Brazil found that highest and lowest values of childlessness are found in developed and less developed regions. For example, 
micro regions that have most indigenous populations present high percentage of childless women. On the other hand, places at the most developed regions of São Paulo State and Rio de Janeiro, which have fertility below 1.6 children per woman had micro regions with few proportions of women who are childless.

The choice of educational field often mirrors a woman's value and preference which may include her attitude regarding reproduction (Hoem et al., 2006). A young woman with strong family preferences may pursue education and even a career, but she is most likely to select herself into the kinds of studies and jobs that are most easily compatible with motherhood (Esping-Andersen et al., 2007).

Bagavos, (2010) expanded the analysis of the relationship between educational attainment, educational field and fertility by presenting the case of Greece. Surprisingly, the study found that the pattern of childlessness by educational field does not explain the diversity of fertility among women. For instance, women trained in teaching and health care have lower levels of childlessness at any educational level than any other major grouping.

The causal relationship between marital status and childlessness has been documented. Based on the Gender and Generations Survey Wave data, Miettinen et al., (2015) explored the associations between childlessness and proportions of married women aged 35-39. The results showed that childlessness remains negatively associated with proportions of married women. However, the study conducted by (Portanti and Withworth, 2009) in Europe where they established lifelong childlessness using Longitudinal Study revealed that single women were most likely to be childless while married women are least likely to be childless.

The results from the study of Matysiak and Vignoli, (2013) that determine the interrelationship between childbearing and women's labor supply in Italy and Poland indicated that in Italy, employed women were found to be far less likely to conceive a first child than women who had never worked or women who had worked in the past, but who had since exited the labor market. For Poland, they found no relationship between women's employment and the transition to a first birth. Specifically, Polish women who had a job were shown to be as likely to enter motherhood as those out of paid work.

Miranti et al., (2009) used this Census question to look at whether more professional women were childless in 2006 compared to 1986. The researchers, concentrated on women aged 20-44 who were childless in selected occupations over twenty years, as well as childlessness for women with tertiary http://aps.journals.ac.za qualifications in different fields. When considering prestigious occupations, the authors found that the proportion of childless women had increased between 1986 and 2006, from about $51 \%$ in 1986 to $60.5 \%$ in 2006. Most of this growth in childlessness occurred between 1986 and 1996. Interestingly, the result from the occupation analysis was that the gap in childlessness between women in prestigious occupations such as professionals and managers had narrowed over the same period.

\section{Theoretical frame work}

Most Southern African Developing countries have experienced shifts in first birth timing toward the older ages. In many of these countries, the incidence of childlessness has also increased. The following section provide a framework which combines the two main driving forces behind the postponement of childbearing as identified by Billari et al., (2006): Firstly, they related postponement of childbearing to Second Demographic Transition (SDT), secondly they pointed to the crucial importance of increasing female human capital accumulation.

The SDT framework suggests that demographic changes including postponement of childbearing are to a large extent due to shifts to the increased individual autonomy, the rise of values associated with the satisfaction of individuals and the growth in gender equality. These changes have led to the emergence of postmodern fertility preferences (Van de Kaa, 200I).

SDT is characterized by low fertility and marriage postponement that leads to long-term subreplacement fertility, decreasing rates of marriage and remarriage as well as increases in cohabitation, divorce, non-marital fertility, childlessness and successful contraceptive use (Lesthaeghe and Neidert, 2006; Lesthaeghe, 2010).

The SDT theory share the same ideology with the Abraham Maslow's theory of changing needs (1954) who theorised that as populations become more wealthy and more educated, the attention shifts away from needs associated with survival, security and solidarity. Instead greater weight is attached to individual self-realization, expressive work and educational values.

Post-Materiastic Values Theory that was developed in the 1970s by Ronald Inglehart share the same ideology with the SDT, this perspective contends that changes in social and demographic behaviour have been driven by the growth of values of self-realisation, satisfaction of personal preferences and freedom from traditional forces of authority such as religion. Low levels of fertility and the rising childlessness have been closely linked to the 
transition theory. As parenthood stops to be the main goal in a woman's life, voluntary childlessness becomes a broadly accepted option (Sobotka, 2008). This has resulted to a rise in the proportion of people who are undecided about whether they will have children later in life. Sobotka and Testa (2008) show that a substantial proportion of childless men and women in Europe do not intend to have a child, or are uncertain about their parenthood intentions.

Billari et al., (2006) emphasised crucial importance of increasing female human capital accumulation. The increasing desire of women to invest in their human capital together with control over their fertility led to the situation in which the decision about the timing of the first birth is a consequence of decision-making process. There is general agreement among scholars that one of the major forces behind the postponement of childbearing is the change in the social roles of women. The changes in family patterns especially the decline of fertility rates below or far below replacement level, have been paralleled by a substantial increase in female labour force participation over time (Bernhardt, 1993; Jokinen and Kuronen, 20I I; OECD, 20I I).

It has been widely argued in the literature that women who have their children early in life are more vulnerable to the negative impact of career interruptions. Having a child as a teenager is associated with lower educational attainment, lower income as an adult and a lower likelihood of marriage (Ng and Kaye, 20I2). Thus women may tend to defer entry into motherhood, choosing instead to invest in their human capital first in order to maximize their life-time earnings. Furthermore, they may be laying foundations for their careers through the achievement of higher degree or fulfilling selfrealisation needs which constitute additional costs of early childbearing (Zabel, 2006).

The study is centered around Billari et al., (2006) framework because central to democracy achieved in 1994 in South Africa, there was a commitment to equality including gender equality and the empowerment of women. The country has statutory and policy architecture for gender empowerment and equality. Indicators related to childbearing such as mean age at first birth, median age at birth, fertility rates, marriage rates and patterns are indicative that women are delaying first child birth and remain childless until elderly ages. To some extent these indicators are linearly associated with women empowerment. South Africa is among emerging economies and thus it generates a demand for a highly educated and flexible workforce. For women, pursuing higher education constitutes the main pathway for finding a stable job, receiving sufficient wage, and increasing career prospects.

\section{Methodology}

To better understand the level of childlessness in South Africa over time and the factors related to childlessness, we relied on South African censuses $200 \mathrm{I}$ and 20II. Amongst all the surveys and censuses, these were the latest censuses with question that parity can be derived. The category of childlessness in this paper captures all women in South Africa aged 20-49 who reported they never had children at the time of censuses. The question that yields this population was asked in both censuses as follows "has the women ever given birth to a child, even if the child died after birth?" The response to the question had four categories: Yes, No, Do not know and unspecified.

The scope of the study comprised of educated women aged 20-49 extracted from censuses 200I and 20I I. In 200I, the total population of educated women aged 20-49 were 934015 whilst the women who reported parity zero were 274 695. For 2011 census, the total population of educated women aged 20-49 were I 448933 whilst those who reported that they never had children in the same age group were 506 733. For the purpose of this paper educated women are those who completed matric and have received some type of level of education (i.e. Certificates and Diplomas, Bachelor degrees and Post higher degrees).

Proportions were used to measure the level of childlessness. The proportions childlessness were determined by dividing the number of educated women aged 20-49 who reported that they did not have children in each age group by total number of women in the same age group. The educated women were categorised into five age groups which were 20-24, 25-29, 30-34, 35-39, 40-44 and 45-49. Women aged 15-19 were excluded from the analysis since they did not complete matric level at the time of censuses $200 \mathrm{I}$ and 20 I I. In this regard, tabulation of educated women was performed by age, marital status, population group, level of education, field of education, employment status, occupation and province.

\section{Main results}

Assessment of missing parity

It is well documented that enumerators often do not record zero parity on the questionnaire to indicate that a woman had never had a child; instead the response is left blank. This is particularly prevalent among younger women. The responses are thus ambiguous, such that it will not be known whether blank is unspecified or represents a childless woman (El-Badry, 196I). If a noticeably large proportion of women are classified under parity not stated, the exclusion of these women will overestimate average 
parities. Conversely, if these women are included in the denominator, the inclusion will underestimate the average parities.

The method was employed to uncertain whether unknown was in actual fact "true" unknown or parity zero. The method was applied to all women 15-49 since the target population of the study is a subset all women in their reproductive age group. The method is applied when the proportion of "not stated" at each age group is higher than $2 \%$. Furthermore, there should be a strong linearity between the unstated parity and parity zero. Table I show that in all age groups, the proportion of women with parity unstated exceeds $2 \%$.

The results from fitting El-Badry indicate that there was no linear relationship between unstated parity and proportion childlessness. This suggests that the missing parity is assumed to be parity zero.

Table I: Distribution of parity by age of women

\begin{tabular}{|c|c|c|c|c|c|c|c|}
\hline \multicolumn{8}{|c|}{ Age group } \\
\hline Parity & 15-19 & $20-24$ & $25-29$ & 30-34 & $35-39$ & 40-44 & $45-49$ \\
\hline 0 & 1527716 & 1017578 & 566391 & 290751 & 188325 & 137200 & 118294 \\
\hline 1 & 291576 & 898301 & 846408 & 492473 & 300345 & 206532 & 170264 \\
\hline 2 & 34802 & 296807 & 600123 & 588898 & 498577 & 389005 & 313890 \\
\hline 3 & 6197 & 59514 & 208317 & 312162 & 359106 & 325900 & 287990 \\
\hline 4 & 1025 & 14840 & 60334 & 121759 & 182705 & 201407 & 198588 \\
\hline 5 & 0 & 4284 & 15771 & 41096 & 79329 & 105206 & 117067 \\
\hline 6 & 0 & 1583 & 7044 & 16581 & 37209 & 56220 & 69561 \\
\hline 7 & 0 & 0 & 3728 & 6289 & 15229 & 27314 & 37390 \\
\hline 8 & 0 & 0 & 1312 & 3955 & 8321 & 14838 & 21537 \\
\hline 9 & 0 & 0 & 0 & 2205 & 3998 & 7537 & 10881 \\
\hline 10 & 0 & 0 & 0 & 898 & 2328 & 4425 & 6667 \\
\hline 11 & 0 & 0 & 0 & 211 & 1252 & 2314 & 3296 \\
\hline 12 & 0 & 0 & 0 & 0 & 687 & 1651 & 2416 \\
\hline 13 & 0 & 0 & 0 & 0 & 127 & 936 & 1428 \\
\hline 14 & 0 & 0 & 0 & 0 & 0 & 587 & 969 \\
\hline 15 & 0 & 0 & 0 & 0 & 0 & 195 & 628 \\
\hline 16 & 0 & 0 & 0 & 0 & 0 & 0 & 422 \\
\hline 95 & 582689 & 311077 & 166272 & 91585 & 63123 & 49734 & 49657 \\
\hline 97 & 6553 & 8798 & 6725 & 3407 & 2061 & 1073 & 686 \\
\hline Total & 2450558 & 2612782 & 2482425 & 1972270 & 1742722 & 1532074 & 1411631 \\
\hline$\%$ parity unstated & 23,78 & 11,91 & 6,7 & 4,64 & 3,62 & 3,25 & 3,52 \\
\hline$\%$ childless & 62,3 & 38,9 & 22,8 & 14,7 & 10,8 & 9 & 8,4 \\
\hline
\end{tabular}

Source: Statistics South Africa, 2 
Figure I: Childlessness among educated and uneducated women aged 20-49, $20 \mathrm{II}$

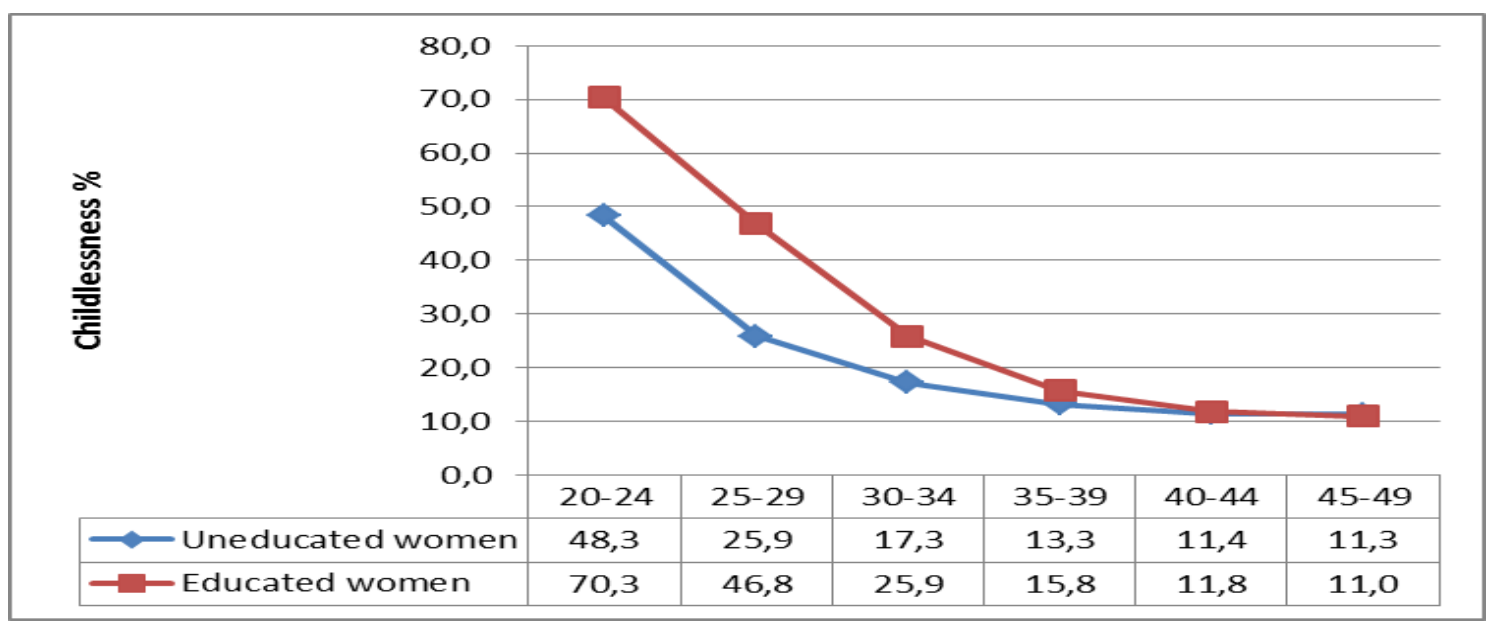

Figure I attests to the above discussions that education influences childlessness. The difference in the levels of childlessness between educated and uneducated women is more distinct between ages 20-34. The level of childlessness among educated women was almost double the level of childlessness among uneducated women between 20-24 and 2529. The difference in childlessness between educated and uneducated women began to narrow at ages 35 and older. The decrease in childlessness proportions by age is an indication of fertility postponement. However, the study in Sweden indicated that at the end of childbearing ages, the majority of the women did not have any biological children (Statistics Sweden, 20I4).

Figure 2: Childlessness of educated women aged 20-49, $200 \mathrm{I}$ and $20 \mathrm{I} \mathrm{I}$

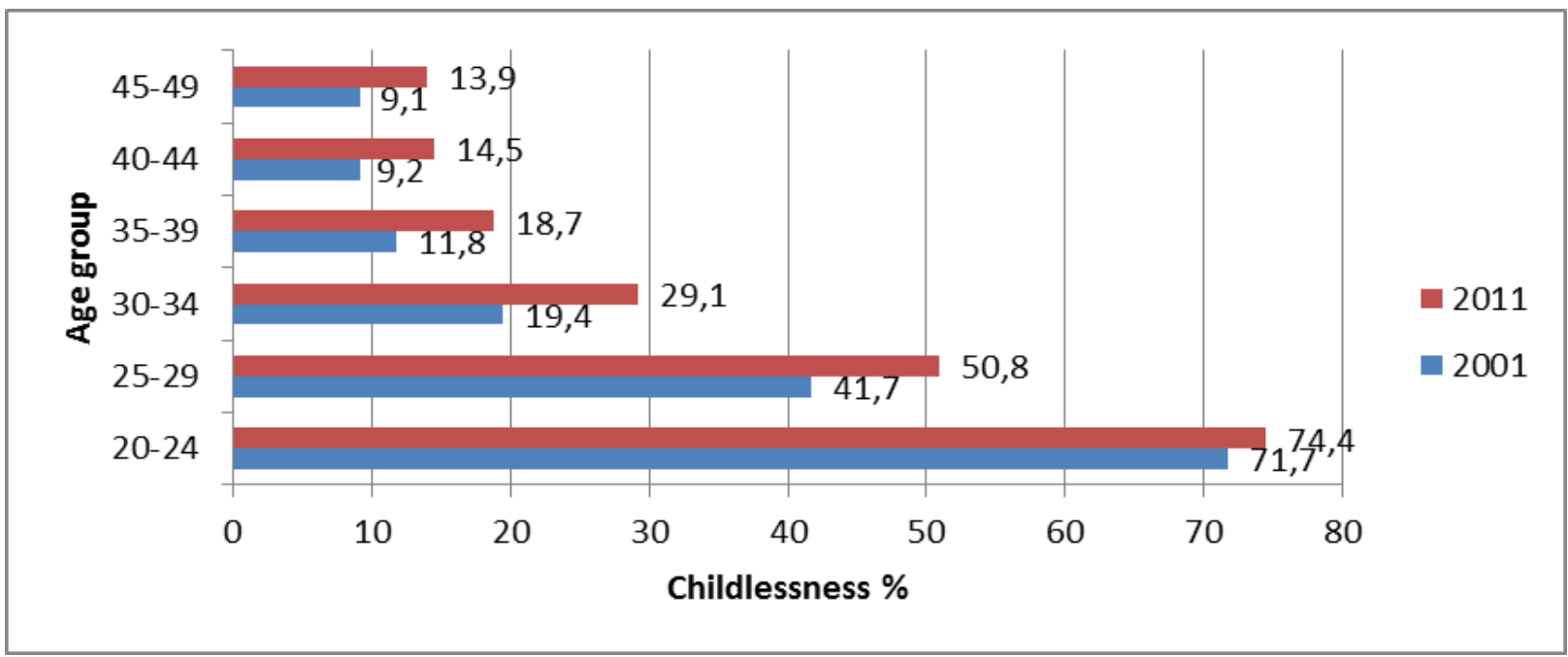

Figure 2 shows that childlessness of educated women increased from 200I to 20ll. The proportion childless among educated women was more distinct at ages 20-24 across time. The margin of increase of childlessness from $200 \mathrm{l}$ to $201 \mathrm{l}$ was higher in educated women aged $25-29(9,1 \%)$ and $30-34$ $(9,7 \%)$. Although childlessness decreased with age of women, the increase in the proportions of childlessness of educated women aged 35 and above is still significant. 
Figure 3: Childlessness of educated women aged $20-49$ by marital status, $200 \mathrm{I}$ and $20 \mathrm{II}$

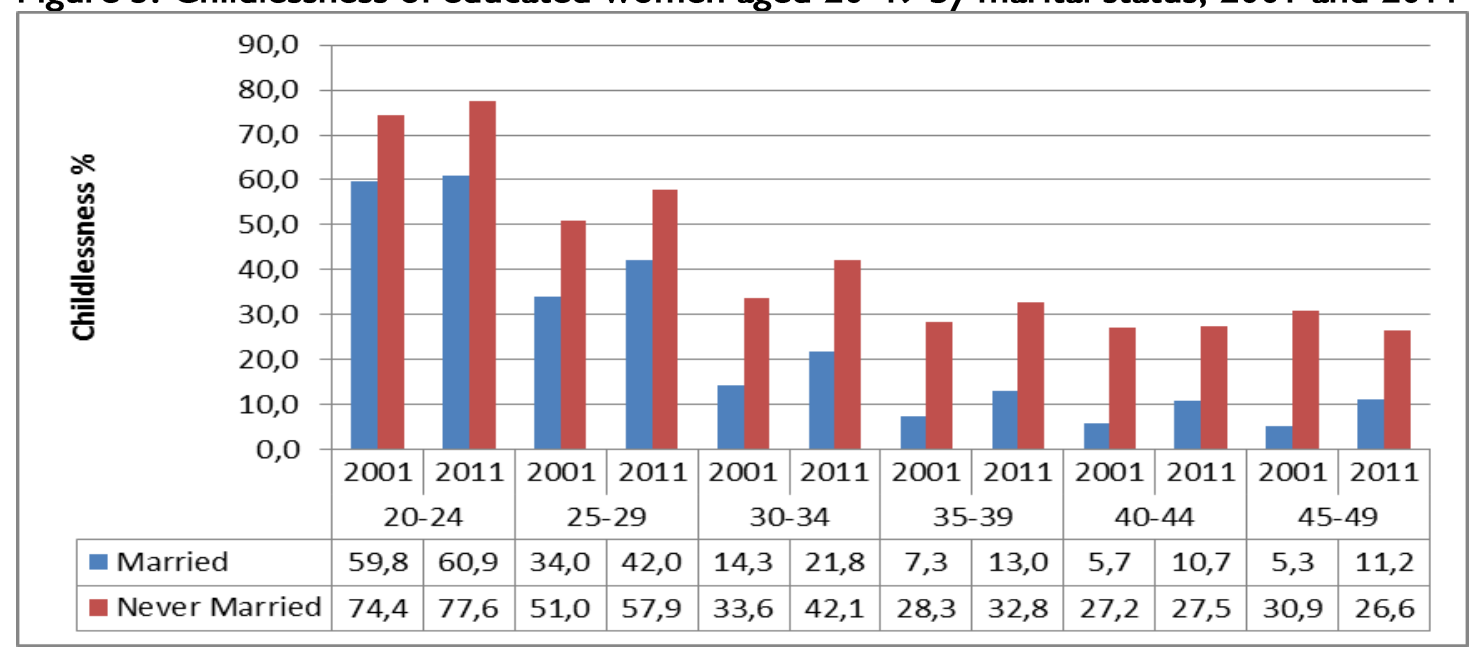

Figure 3 indicates that, over time and across all marital categories, never married women aged 20-49 recorded high prevalence of childlessness. What is striking is that even at ages 25-29 there was an increase of about $8 \%$ point of childlessness amongst educated women who were married from 2001 to 201 I. The gap in childlessness between educated unmarried and married women increased significantly from women aged 30-34 and older.

Figure 4: Childlessness of educated women aged $20-49$ by population group, 200 I and 20I I Censuses

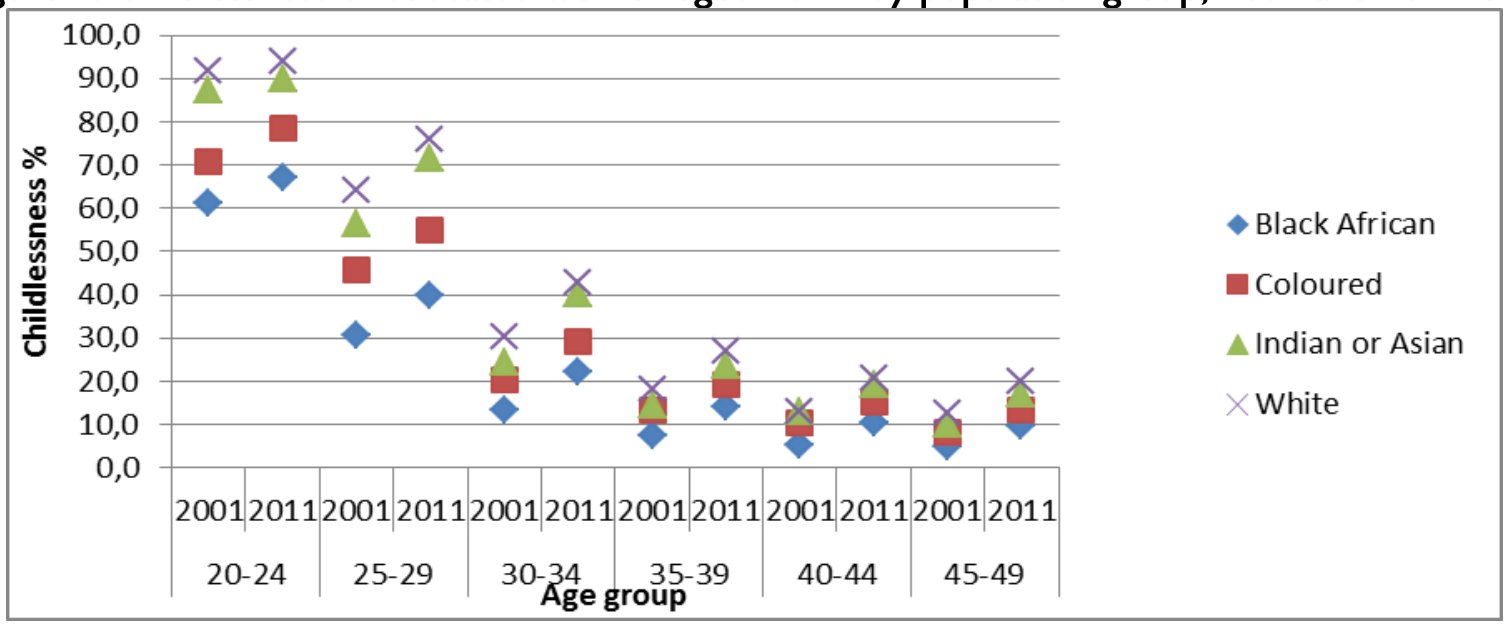

The results in figure 4 suggest that black African educated women followed by coloured had greater risk of becoming mothers than remaining childless compared to white educated women. This is expected because of the low mean age at first birth and the high fertility rates characterizing these populations. The pattern remained almost unchanged during the period 200I-20II. Despite the increase of childlessness across all the population groups, whites and Indians/Asian had the highest number of women who were childless, particularly among women aged 20-29. The findings are not surprising as the Age Specific Fertility Rate (ASFR) of the population groups peaked between the ages 25 and 35 . 
Figure 5: Childlessness of educated women aged 20-49 by level of education

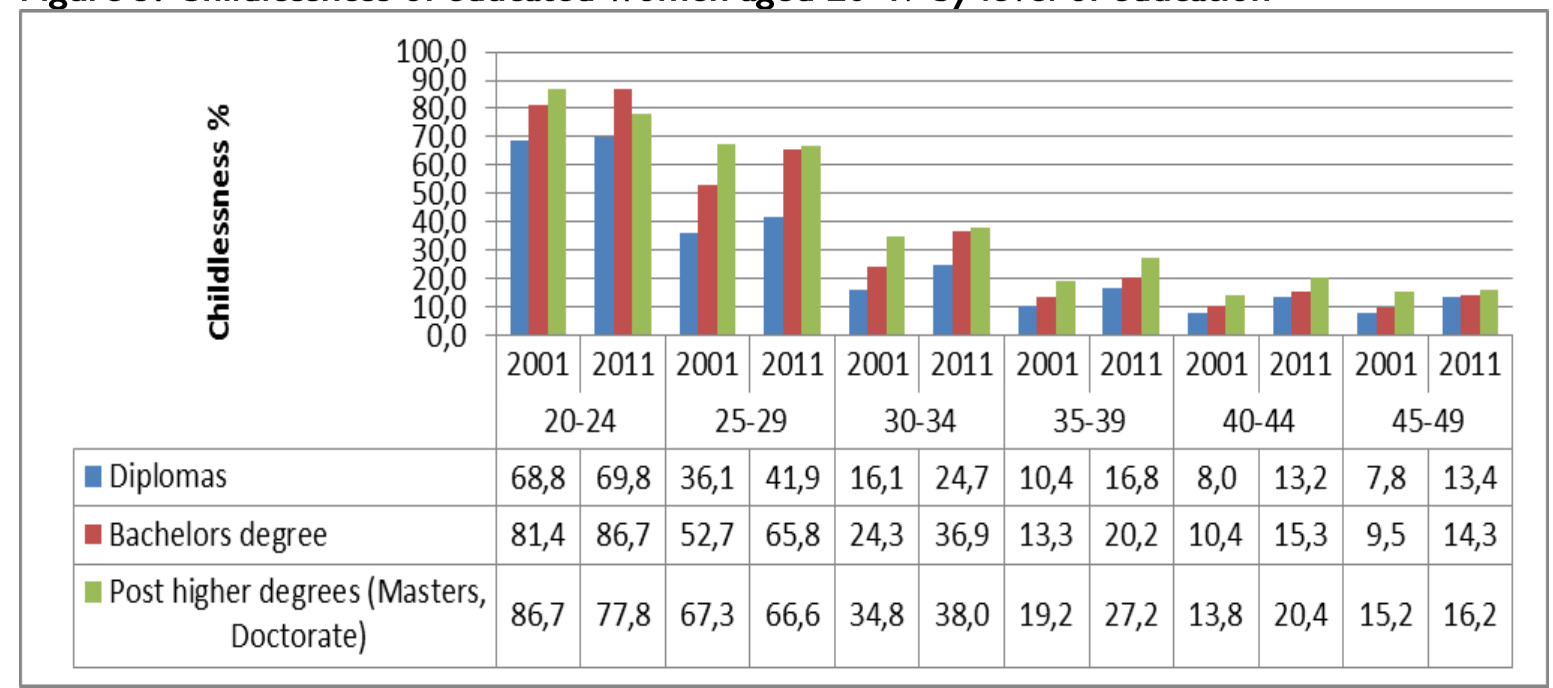

Figure 5 presents childlessness of educated women by level of education. Education of the women shows significant association with childlessness. As the education of women increases the level of childlessness also increases. Overall in all the years, women with post higher degree appeared to have no children than those who have diplomas and bachelors across all age groups. Across all levels of qualifications, women with diplomas recorded the lowest prevalence of childlessness. In recent years, a very rapid socio-economic development experienced by South Africa has contributed to a significant improvement in the status of women through expanding education (Palamuleni, 2010). The proportions of young people who attain higher education have been rising with each successive cohort and educational differentials are influencing fertility trends on the aggregate level (Klesment, 2010).

There were slight differences in the prevalence of childlessness between women with bachelors and post higher degrees particularly in younger age groups. Both groups recorded on average childlessness of over $80 \%$ for women aged $20-24$ and almost $60 \%$ for subsequent age group (25-29). The proportion of childless women with post higher degrees among young women aged (20-24) decreased markedly from 86,7 in 2001 to 77,8 in 2011 .

Figure 6: Childlessness of educated women aged $20-49$ by employment status

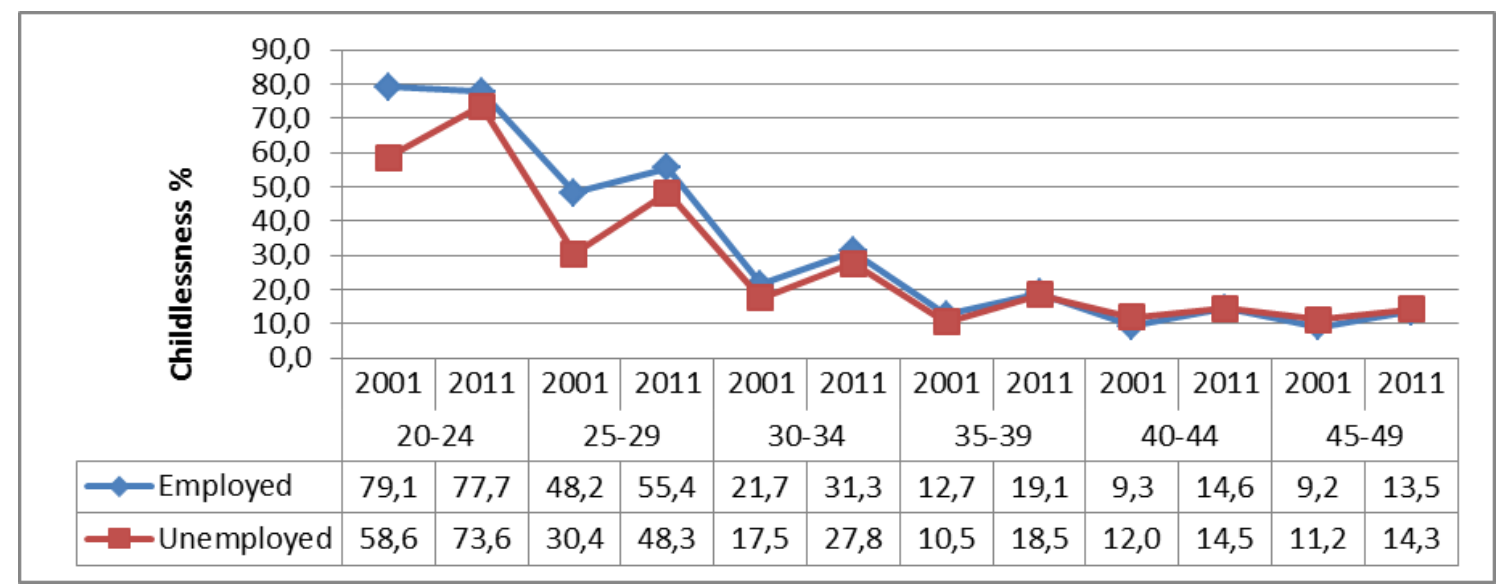

NB: Official definition of employment was used in the analysis

Figure 6 focuses on the differences in childlessness between educated women who were employed and unemployed. The prevalence of childlessness increased over time and across employment status in all age groups. Employed educated women seemed to be childless than unemployed in the period studied, however, the gap began to close from ages 30 and above. This is an indicative that the desire to have children amongst educated women increases as age increases irrespective of the employment status. 
African Population Studies Vol. 30, No. 2 (Supp.), 2016

Table 2: Childlessness of educated women aged 20-49 by occupation

\begin{tabular}{l|c|c|c|c|c|c|c|c|c|c|c|c}
\hline \multirow{2}{*}{\multicolumn{1}{c}{ Occupation }} & \multicolumn{2}{|c|}{$20-24$} & \multicolumn{2}{c|}{$25-29$} & \multicolumn{2}{c|}{$30-34$} & \multicolumn{2}{c|}{$35-39$} & \multicolumn{3}{c|}{$40-44$} & \multicolumn{2}{c}{$45-49$} \\
\cline { 2 - 11 } & 2001 & 2011 & 2001 & 2011 & 2001 & 2011 & 2001 & 2011 & 2001 & 2011 & 2001 & 2011 \\
\hline Manager & 88,0 & 79,5 & 59,1 & 60,4 & 34,5 & 33,9 & 20,1 & 21,1 & 11,7 & 13,6 & 10,6 & 14,2 \\
Professional & 86,3 & 80,8 & 61,0 & 60,9 & 28,5 & 32,5 & 15,8 & 17,1 & 12,0 & 12,1 & 10,8 & 10,7 \\
Technician & 79,3 & 69,1 & 42,3 & 45,0 & 15,7 & 24,7 & 9,5 & 14,3 & 7,0 & 10,5 & 6,9 & 9,6 \\
Clerk & 76,5 & 74,0 & 43,9 & 50,7 & 20,2 & 27,4 & 10,6 & 16,4 & 8,5 & 13,2 & 9,3 & 11,8 \\
Sales and services & 78,5 & 74,3 & 43,0 & 48,6 & 21,7 & 27,3 & 15,3 & 16,5 & 10,2 & 13,4 & 12,0 & 10,6 \\
Skilled agriculture & 94,6 & 65,4 & 38,6 & 45,1 & 16,5 & 38,6 & 18,4 & 22,4 & 4,4 & 14,0 & 11,4 & 9,7 \\
Craft and related trade & 64,9 & 75,4 & 41,0 & 46,4 & 20,0 & 27,6 & 9,8 & 13,6 & 18,7 & 10,8 & 11,7 & 10,4 \\
Plant and machine operator & 74,4 & 72,4 & 40,4 & 46,5 & 22,5 & 23,9 & 8,7 & 13,0 & 6,6 & 9,5 & 15,6 & 12,0 \\
Elementary & 64,2 & 68,2 & 28,5 & 47,0 & 16,7 & 23,1 & 13,8 & 14,9 & 10,1 & 12,1 & 12,3 & 9,4 \\
\hline \hline
\end{tabular}

Table 2 indicates that occupational differences among educated women exist significantly, but the results revealed a diverse pattern of childlessness. Over time and across all the age groups the proportion childless was high amongst professionals and managers and low among educated women with elementary occupation. Interestingly, at elderly ages 35-44, educated women who were plant and machinery operators had lowest childlessness than those within elementary occupation. Within the same age group in 20II, childlessness was significantly higher amongst women with skilled agriculture relative to all occupations.

Figure 7: Childlessness of educated women aged $20-49$ by field of education, $201 \mathrm{I}$

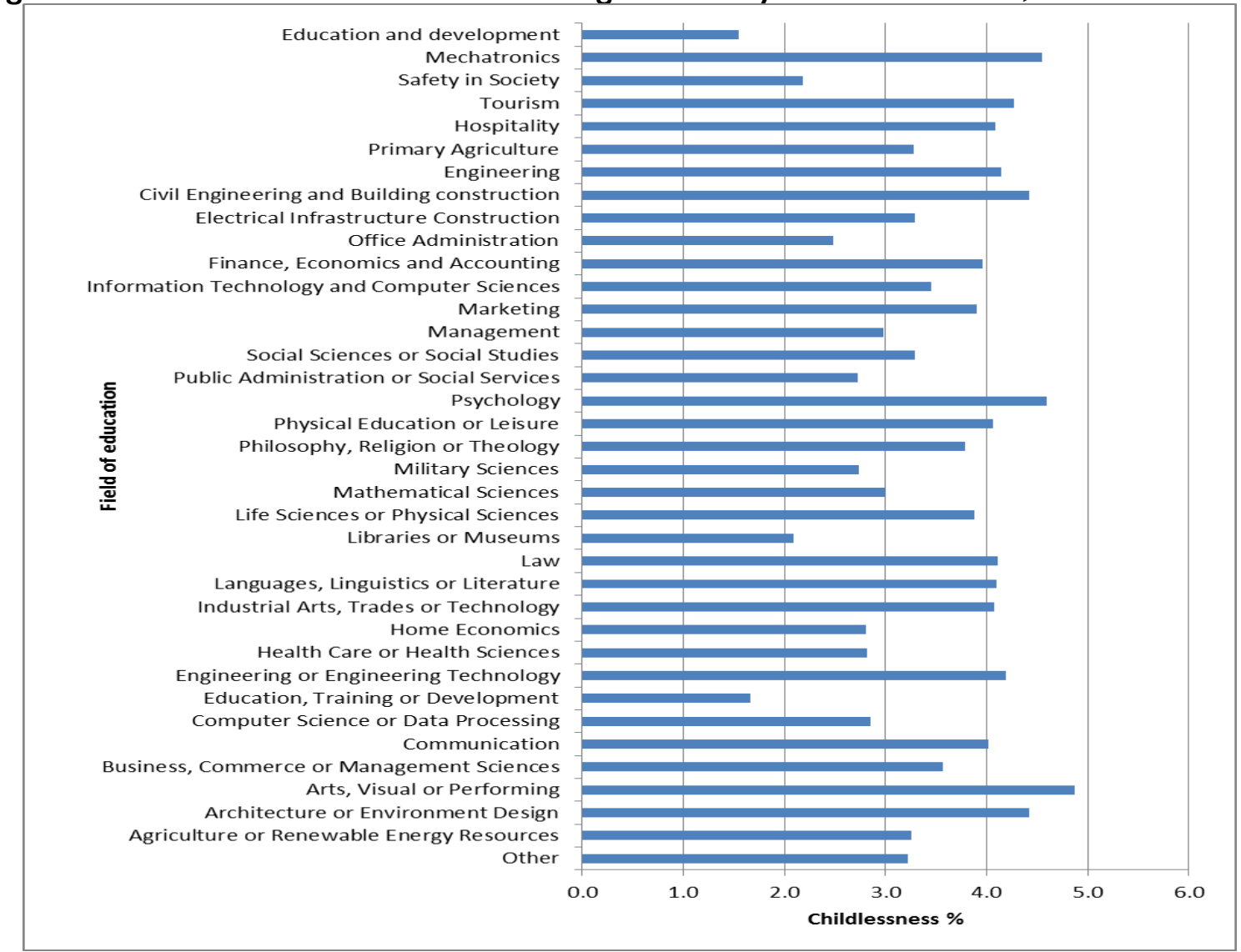


Field of study have been proven to be both theoretically an empirically relevant for women's transition to first and it serves better as an indicator of a woman's potential reproductive behaviour than the educational level attained (Bagavos, 20I0). Across all the fields, the majority of educated women who were childless were trained in the fields of mechatronics, psychology, engineering, visual or performance arts, tourism and law. Educated women trained in arts, mechatronics and psychology had on average the highest prevalence of childlessness of $47 \%$. The second highest childless women were amongst others in the field of linguistics, hospitality and communication. The lowest levels of childlessness were found among educated women trained in administration, safety in society, education and training and development.

Table 3: Childlessness of educated women aged 20-49 by province

\begin{tabular}{|c|c|c|c|c|c|c|c|c|c|c|c|c|}
\hline \multirow[b]{2}{*}{ Province } & \multicolumn{2}{|c|}{$20-24$} & \multicolumn{2}{|c|}{$25-29$} & \multicolumn{2}{|c|}{$30-34$} & \multicolumn{2}{|c|}{$35-39$} & \multicolumn{2}{|c|}{$40-44$} & \multicolumn{2}{|c|}{$45-49$} \\
\hline & 2001 & 2011 & 2001 & 2011 & 2001 & 2011 & 2001 & 2011 & 2001 & 2011 & 2001 & 2011 \\
\hline WC & 82,6 & 85,9 & 59,1 & 66,9 & 32,4 & 41,5 & 18,8 & 24,9 & 15,0 & 21,2 & 16,1 & 17,9 \\
\hline $\mathrm{EC}$ & 72,0 & 67,5 & 37,0 & 46,3 & 15,4 & 25,5 & 9,4 & 16,0 & 6,5 & 12,1 & 7,4 & 11,1 \\
\hline $\mathrm{NC}$ & 71,0 & 74,5 & 37,3 & 46,7 & 18,7 & 29,5 & 10,3 & 12,1 & 9,2 & 12,2 & 7,9 & 14,0 \\
\hline FS & 74,0 & 74,2 & 40,8 & 47,3 & 13,3 & 25,8 & 9,7 & 16,3 & 6,9 & 10,9 & 6,4 & 10,7 \\
\hline $\mathrm{KZN}$ & 68,4 & 70,8 & 40,3 & 47,2 & 18,5 & 27,6 & 11,6 & 18,7 & 8,5 & 14,5 & 7,6 & 13,9 \\
\hline NW & 67,8 & 72,6 & 33,2 & 41,0 & 12,5 & 20,7 & 7,3 & 12,7 & 6,8 & 8,3 & 7,0 & 8,5 \\
\hline GP & 75,1 & 78,3 & 47,4 & 54,8 & 24,5 & 31,2 & 14,8 & 21,2 & 10,7 & 16,8 & 9,9 & 17,1 \\
\hline MP & 60,3 & 61,5 & 30,2 & 35,9 & 11,8 & 20,8 & 8,7 & 11,4 & 6,2 & 10,6 & 6,7 & 9,8 \\
\hline LP & 49,8 & 60,4 & 20,5 & 31,3 & 9,0 & 13,5 & 5,1 & 9,5 & 4,1 & 6,5 & 2,7 & 7,2 \\
\hline
\end{tabular}

Table 3 shows spatial variation of childless women in South Africa between $200 \mathrm{I}$ and 201I. Variations in childlessness of educated women have been observed in different provinces. Over time childlessness among educated women was higher in Gauteng and Western Cape. In 20I I, at the peak age of childbearing (25-29) 2 in 3 women were childless in Western Cape. Within the same period, Limpopo and Mpumalanga had the lowest levels of childlessness. The spatial pattern revealed in this analysis is probable because it reflects the fertility patterns, behavior and socio-economic differentials in these provinces.

\section{Discussions and conclusions}

Despite variations in socioeconomic differentials, the results presented provide strong evidence that childlessness in South Africa, increased from 200I to 2011. The results showed childlessness decreased from women aged 30-34. The most important indicator of the decrease in childlessness of women appeared to be delaying first birth. The decline in the levels of childlessness overtime could be attributed to the fact that South Africa achieved a considerable progress in many aspects of women's empowerment that increased educational attainment, labour market participation, access to credit, land and properties and share of paid work. The results are consistent with some of the conclusions reached by other investigators.

Nicoletti and Tanturri, (2008) in the study of ten countries conducted in Europe the authors found that higher female education increased postponement of the first birth particularly after age 30.

Population differentials indicate that among all women, white and Indian/Asian women experience higher levels of childlessness across all ages. It is not surprising as the two populations had fertility rates of below replacement level of 1,7 children per women 
and 1.9 children per woman respectively. This pattern ties with the level of socio economic development amongst these populations. Large families have remained the norm amongst black African and coloured in South Africa (Stats SA, 2015).

The study further indicate that women with post higher degree and bachelors degree were more likely to be childless than those with diplomas. The results confirm the human capital framework that predicts that women's increasing education postpones and reduces motherhood. South African scholars (Moultrie and Timaeus, 200I) in the study of the determinants of fertility established that indeed educated women had the lowest number of children than their counterpart. The high levels of childlessness amongst the most educated women could be attested to the improvement of policies relating to women's education in the country. The finding concur with the study of Billari et al., (2006) who have related delaying of parenthood to the increase of years spent in education, the difficulties to combine work and family life and to growing economic uncertainty in Europe.

The results indicate that, overall the level of childlessness is higher among the employed than unemployed. However the gap of childlessness among the employed and unemployed begin to narrow from age 30 and above. The same pattern is evident among educated women with income and without income. The pattern suggests that even if educated women are not employed and do not earn income they remain childless until older ages.

The degree of compatibility between work and family life, tends to mediate the effect of education on fertility (Kreynefeld and Konientza, 2008). This is expected for highly educated women who have strong career aspirations. In countries where work and family life are hard to reconcile, we would expect a higher rate of childlessness among highly educated women.

In comparison, educated unmarried women indicate higher levels of childlessness over time. Haskey, (20/3) also noted that the longer the period of time spent outside a partnership between the ages of 16 and 45, the larger the proportions of men and women who were childless. Several authors have suggested that rather than explicitly choosing childlessness, people make choices about delaying marriage and focusing on educational and occupational careers, and then end up childless (De Meester et al., 2005). Due to increased status of women in South Africa, perhaps educated, unmarried women choose the opportunity of building a career and securing a job before they can embark on family formation.

The findings from the study indicated that the majority of educated women who were childless were in the field of psychology, engineering and art or performance. Data also revealed that higher education alone does not result in higher childlessness. Better educated women trained in educational development and relational skills category showed lower levels of childlessness with respect to those in other categories at the same education level. The hypothesis is attested by (Esping-Andersen et al., 2007). They observed that when a young woman with strong family preferences pursue education and a career, she is most likely to select herself into the kinds of studies and jobs that are most easily compatible with motherhood. Lappegård and Rønsen, (2005) revealed that fertility is highly structured by field of study. Women who are in the fields that are more male-dominated may consider their identity and self-fulfillment than being mothers.

Professional psychology in South Africa is following the trends of other countries and is steadily becoming a profession dominated by women. There has been suggestions explaining this abroad and in South Africa, but there are no clear explanations. Amongst the general explanations are gender socialisation and women numerical increase in the labour market. This increase of childlessness among this field could be due to increasing proportion of women enrolling in psychology at universities around the country.

Childless was high amongst professionals and managers and low amongst educated women with elementary occupation. There has been strong recent growth in women's representation in the labour force including in professional occupations. These changes have significant implications for family building experiences, including women's child bearing patterns.

Despite the levels and trends of childlessness explored from censuses data, studies of fertility behaviour and expectations of childbearing in South Africa are surrounded by several important gaps. Firstly, the available surveys and national censuses do not provide means to differentiate voluntary and involuntary childlessness. This could bias the conclusions derived from the studies. Secondly, the decision to have children depends on both man and women therefore, it would be interesting to further build literature around childlessness when measurement could include husband or partners. 


\section{Limitations}

The main limitation of the study is that one cannot distinguish between involuntary childlessness (infertility), intended childlessness (those who do not intend to have children), voluntary childlessness (the childfree), and temporary childlessness related to circumstantial or delayed childbearing, which is neither voluntary nor involuntary (Graham et al., 20I3). Thus, the researchers could not measure and monitor the trends effectively.

Since the researchers used a fraction of the population from censuses, multivariate analysis could not be used due to larger proportions of women under study. There are many advantages to large samples, however when using statistical inference, one must be aware of the p-value problem associated with them. In very large samples, $p$-values are often zero and relying on them can lead the researcher to claim support for results of no practical significance. The conclusion of the study will only be based on bivariate analysis (Lin et al., 2013).

\section{Conclusion}

The study was an attempt to understand trends and levels of childlessness among educated women in South Africa. The research was formulated based on the current understanding of decreasing fertility as revealed by the available literature. The main areas of the research included the socio economic factors that might influence on childlessness in South Africa. The main results of the study are in two folds, firstly the educational differentials in childlessness are not narrowing over time, but they remain large, and increasing. Secondly, childlessness begins to decrease as age increases. Postponing childbearing seems to be a suitable strategy that allows women to achieve a high degree of education, establish themselves in the labour market, stabilize their relationships before childrearing and deal with unstable life.

The increase in the level of childlessness is a concern to any country. South Africa is not an exception, it has relatively the lowest fertility rates in Sub-Saharan countries. These together with the increasing trends in childlessness have affected the population age-sex structure. South Africa is characterized by a structure that is indicative of low levels of childbearing and mortality. As the total fertility decreases, the proportion of children aged $0-14$ begins to decrease relative to the population aged 15-64. This demographic transition does not automatically accelerate economic growth. In sub-Saharan countries and elsewhere, where fertility is declining, it is vital to establish an enabling policy environment for youth to benefit from education, health, employment opportunities and livelihood creation to become productive adult workers in the near future (USAID, 20I2). Unemployment is a huge area of concern recently. The government should redirect resources to create policies that must generate employment opportunities for the youth bulge created by high levels of childlessness.

In addition, South Africa experienced the declining mortality rates and the increase in life expectancy since 2006 (Stats SA, 2015). This mortality pattern increased the proportion of the ageing population substantially. The kind of demographic change in South Africa is seen as a challenge for many policy areas such as social protection systems, pensions and long-term care for elderly population. Many of these areas involve a significant share of public finance expenditure, for instance, the government must maintain and increase the adequacy of pension benefits, which are the main source of income for elderly population.

\section{Reference}

Beksinska M, Smit J, Mantell J. 20I2. Progress and challenges to male and female condom use in South Africa. Sexual Health, 9, (I): 5I-58

Health Systems Trust. 2009. Health Statistics: HIV prevalence (\%). Durban: Health Systems Trust.

Hoffman, S., Mantell, J., Exner, T., \& Stein, Z. 2004. The future of the female condom. Perspectives on Sexual and Reproductive Health, 36, (3): I 20- I 26.

MacPhail, C., Pettifor, A. E., Pascoe, S., \& Rees, H. V. 2007. Contraception use and pregnancy among 15-24 year old South African women: a nationally representative cross-sectional survey. Bio Medical Central Medicine, 5, I-8.

Mantell, J. E., Smit, J. A., Jennifer, A., Beksinska, M., Scorgie, F., Milford, C., Balch, E., Mabude, Z., Smith, E., Adams-Skinner, J., Exner, T.M., Hoffman, S., \& Stein, Z. A. 20II. Everywhere you go, everyone is saying condom, condom. But are they being used consistently? Reflections of South African male students about male and female condom use. Health Education Research, 26, (5), 859-87I.

Marston, C., \& King, E. 2006. Factors that shape young people's sexual behaviour: a systematic review. Evidence Based Nursing, 10, (4), I 24.

Mathenjwa, T., \& Maharaj, P. 20I2. Female condoms give women greater control': a qualitative assessment of the experiences of commercial sex workers in Swaziland. European Journal of Contraceptive Reproductive Health Care, 17, (5), 383-392.

Nakari, T., \& Huurne, D. 2010. The condom gap, widening or narrowing? IPPF. 
Sarkar, N. N. 2008. Barriers to condom use. The European Journal of Contraception and Reproductive Health Care, 13, (2), II4-122.

Njagi, F., Maharaj, P. 2006. Access to Voluntary counseling and testing services: Perspectives of young people. South African Review of Sociology, 37, (2): I I3-127.

Peltzer, K., Mzolo, T., Mbelle, N., Tsoai, L., Lewa, N., \& Ncitakalo, N. 20I0. Dual protection, contraceptive use, HIV status and risk among a national sample of South African women. Gender and Behaviour, 8, 2833-2845.

Peters, A., Van Driel, F. \& Jansen, W. 2014. Acceptability of the female condom by subSaharan African Women: A Literature Review. African Journal of Reproductive Health, 18, (4): 34-44.

Seedat, F. 20II. What is hindering female condoms from preventing HIV transmission? The progress of policy thus far. Consultancy Africa Intelligence
Seutlwadi, L. 2012. Contraceptive use and associated factors among South African youth: A populationbased survey. South African Journal of Obstetrics and Gynecology, I8, (2): 43-47.

Shisana, O., Rehle, T., Simbayi, L.C., et al. 2014. South African National HIV Prevalence. Incidence and behaviour survey, 20I2. Cape Town: HSRC Press.

Statistics South Africa. 2007. Community Health Survey 2007: Basic Results- Municipalities. Statistics South Africa: Pretoria.

Strode, A., Slack, C., \& Essack, Z. 2010. Child consent in South African law: implications for researchers, service providers and policy makers. South African Medical Journal, 100, 247-247.

Willan, S. 2013. A Review of teenage pregnancy in South Africa-experiences of schooling, and knowledge and access to sexual \& reproductive health services. Partners in Sexual Health. 